\title{
O QUE ESPERAR DOS DEPUTADOS FEDERAIS ELEITOS POR GRUPOS DE RENOVAÇÃO POLÍTICA NO BRASIL?
}

Roberta Picussa ${ }^{1}$

\begin{abstract}
Resumo $^{2}$
Este artigo tem como objetivo investigar os eleitos advindos de grupos organizados de renovação política suprapartidários, com foco no RenovaBR, no Movimento Acredito e no Movimento Brasil Livre. Pretende-se desvendar: (1) quais são as principais características desses grupos; e (2) qual é o perfil e como se comportam na arena parlamentar os integrantes que se elegeram à Câmara dos Deputados (CD) no pleito de 2018. A hipótese é de que os representantes desses grupos apresentam perfil político e comportamento parlamentar incomuns quando comparados ao total dos deputados federais eleitos em 2018 A primeira parte da pesquisa foi realizada por meio da exploração das informações disponíveis nos sítios eletrônicos dos grupos, bem como, nas contas de Twitter e Instagram deles e de seus representantes no Congresso. Para responder à segunda questão foi realizado um levantamento estatístico de dados dos deputados eleitos à Câmara Federal em 2018, destacando as seguintes características: raça, sexo, idade, escolaridade, ocupação e tipos de financiamento de campanha. Para aferir o comportamento parlamentar foi realizado um levantamento do posicionamento dos deputados objeto dessa pesquisa no conjunto de votações nominais referentes à Proposta de Emenda Constitucional nº 6/2019 - PEC da Previdência, por meio de testes estatísticos realizados no software Phyton, foi mensurado o nível de associação dos votos dos parlamentares e as orientações dos seus respectivos partidos, bem como, entre todas as orientações dos partidos e todos os votos dos parlamentares entre si. Os resultados mostraram que o perfil dos deputados advindos de grupos de renovação política não apresenta inovações comparado ao total dos eleitos à $\mathrm{CD}$, com exceção dos quesitos "ocupação" e "idade". Quanto ao comportamento, a maioria deles votou de forma alinhada aos respectivos partidos, e não aos grupos suprapartidários, com exceção dos membros do Movimento Acredito.
\end{abstract}

Palavras-chave: partidos; comportamento parlamentar; renovação política; perfil parlamentar; financiamento de campanha.

\footnotetext{
${ }^{1}$ Universidade Federal do Paraná, e-mail: betapicussa@gmail.com. ORCID: https://orcid.org/0000-0002-5400-5136.

${ }^{2}$ Os gráficos e tabelas referentes à análise estatística das votações nominais que constam neste artigo foram elaboradas por Victor Garcia Miranda, Professor Adjunto do curso de Ciências Sociais da Universidade Federal de Mato Grosso do Sul, a quem eu agradeço pela contribuição.
} 


\section{INTRODUÇÃO}

O júri especializado do prêmio Congresso em Foco elegeu Tabata Amaral como a melhor deputada da Câmara Federal em 2019. O prêmio, geralmente concedido a deputados experientes, foi uma surpresa para muitos, já que Tabata, de apenas 25 anos, trata-se de uma novata na política. Ela ganhou destaque na mídia depois de fazer duras críticas ao ex-ministro da Educação Ricardo Veléz, em reunião da Comissão de Educação na Câmara, em março de 2018.

A jovem já disse em entrevistas que sua presença na Câmara causa estranheza para os colegas parlamentares, que não entendem qual foi o seu capital político para chegar até lá, já que não é filha nem esposa de nenhum político importante, nem uma influencer digital, tampouco tem histórico de militância estudantil ou partidária. Sua história é realmente incomum, pois se trata de uma jovem que cresceu na pobre periferia de São Paulo, mas conseguiu se destacar o suficiente para ganhar bolsas em bons colégios até chegar a Universidade de Harvard, onde estudou astrofísica e ciência política, e logo após se formar, voltou ao Brasil porque dizia acreditar que poderia contribuir para melhorar o país em que nasceu.

Tabata é um dos exemplos de uma nova geração de políticos que podem ocupar os espaços de poder político num futuro próximo. Ela faz parte de duas organizações suprapartidárias de renovação política, o RenovaBR e o Movimento Acredito. O primeiro praticamente financiou sua candidatura, e o segundo é ao qual ela parece prestar contas de seu mandato.

Este artigo tem como objetivo investigar o perfil e o comportamento parlamentar dos eleitos advindos de grupos organizados de renovação política suprapartidários, com foco nas organizações supracitadas. Os objetivos são desvendar (1) quais são as principais características desses grupos; e (2) qual é o perfil e como se comportam na arena parlamentar os integrantes que se elegeram à Câmara dos Deputados no pleito de 2018. A hipótese é de que os representantes desses grupos apresentam elementos inovadores em seu perfil político e comportamento parlamentar incomum, quando comparados ao total dos deputados federais eleitos em 2018.

Essas organizações têm em comum o protagonismo de outsiders na política e o objetivo de colocar em prática o plano de renovar a forma de fazer política no Brasil por meio da formação de novas lideranças políticas. Mas há muitas particularidades no perfil de cada grupo.

O RenovaBR se define em seu sítio eletrônico como "uma iniciativa que nasceu na sociedade civil, com o objetivo de preparar novas lideranças para entrar para a política. Não somos um partido político, nem apenas um movimento. Somos uma iniciativa de formação de lideranças e de 
engajamento cívico". Nesse espírito, cerca de quatro mil pessoas de todo o Brasil se candidataram para serem formados pelo projeto em 2017. Os selecionados, 133 "líderes" entre candidatos a deputado federal e estadual, passaram por um processo de 60 horas de formação com especialistas bem conceituados em áreas que vão de educação a saúde pública, de gestão fiscal ao desenvolvimento social, para aprenderem "tudo o que um político deveria saber", de acordo com a concepção dos fundadores do grupo. Para que eles pudessem se dedicar exclusivamente a seus processos de formação, receberam bolsas mensais, entre janeiro e julho de 2018, que variavam de 5 a 12 mil reais. No pleito de 2018, 16 líderes foram eleitos, sendo dez ao Congresso Nacional e seis às Assembleias Legislativas Estaduais. Ao todo, integrantes do RenovaBR receberam mais de 4,5 milhões de votos.

Em 2019, o RenovaBR lançou o processo seletivo para as eleições municipais, como resultado teve 31.359 inscritos em 2.099 cidades do país. 61\% deles não é filiado a nenhum partido político. Dentre os inscritos, o grupo selecionou 1,4 mil pessoas para passarem pelo processo de formação política e concorrer a um cargo nas eleições municipais de 2020. O grupo conta com 17 empresas parceiras, entre elas as gigantes Gol Linhas Aéreas e a Kroll Consultoria.

O Acredito, por sua vez, se identifica como "movimento", tem agendas bem delineadas quanto ao tipo de mudança que pretende promover na política, e tenta emplacar o discurso de que a agenda pública e o compromisso com ética e transparência estão acima de ideologias. Em seu sítio eletrônico não há nenhuma menção de alinhamento à direita ou à esquerda, em vez disso, há afirmações como "acreditamos em um Estado eficiente e menos engessado. Rechaçamos a disputa simplista entre estado grande e mínimo. Acreditamos que este deva garantir o acesso adequado a bens e serviços públicos de qualidade".

O movimento atua para além da esfera política institucional, e possui diversas lideranças cívicas, que se comprometem a desenvolver ações em prol da sociedade nas mais variadas esferas. Entre elas, 25 se candidatam nas eleições de 2018 e três se elegeram ao Congresso Nacional.

Já o Movimento Brasil Livre (MBL), é a organização mais difícil de caracterizar. Primeiramente porque no sítio eletrônico do movimento existem poucas informações sobre ele. Ao invés de ícones como "quem somos", o site tem vídeos com os jovens líderes do movimento contando histórias conspiratórias, combinadas com imagens de protestos e acontecimentos políticos, entre outras referências. Em um deles, a ideologia de esquerda é uma inimiga infiltrada em vários espaços (governo, jornais, escolas), que deve e vai ser combatida por eles. Os vídeos têm várias simbologias que escapam à capacidade analítica deste artigo, mas é importante pontuar o forte apelo a uma juventude revolucionária contido neles. Aparenta ser um movimento feito por jovens para outros 
jovens. Na conta do Twitter do movimento, consta a seguinte definição: "O Movimento Brasil Livre é uma entidade suprapartidária que visa a mobilizar cidadãos em favor de uma sociedade mais livre, justa e próspera".

O sítio eletrônico do movimento contém um compêndio de propostas que foram definidas em um Congresso de membros realizado em 2015, e apontam para uma agenda de extrema direita. Dentre as propostas, na educação, a "militarização das escolas em áreas de risco, ou seja, em locais onde a iniciativa privada não tenha a possibilidade de atuar", a "gestão privada de escolas públicas através de Organizações Sociais e Parcerias Público-Privadas". Na saúde, a "adoção de um sistema de saúde similar ao alemão em substituição ao SUS: obrigatoriedade da contração de um plano de saúde e fornecimento de plano gratuito para aqueles que não puderem pagar por um". Na cultura, a revogação da Lei Rouanet. No sistema político, o fim do voto obrigatório, fim do fundo partidário, e a possibilidade de candidaturas independentes para Executivo e Legislativo. Na economia, a privatização de todos os bancos, a "revisão do capítulo econômico da Constituição (adotar a economia de mercado. Qualquer interferência do Estado deverá ser justificada e seus resultados, posteriormente avaliados)". Entre várias outras propostas não elencadas aqui. ${ }^{3}$

Na eleição de 2018, o MBL elegeu Kim Kataguiri, filiado ao DEM, como deputado federal com 465.310 votos, foi um dos cinco deputados mais votados do Brasil.

Considerando que essas organizações desempenham, em grande medida, funções muito semelhantes a dos partidos políticos, como o recrutamento e a formação de novas lideranças políticas, bem como, a mobilização da sociedade para pautas políticas e sociais específicas, esse artigo se propõe a investigar que tipo de elite política essas organizações levaram à Câmara Federal em 2018, com uma questão sempre em mente: que tipo de inovações elas realmente apresentam?

\section{MATERIAIS E MÉTODOS}

Para responder às questões que norteiam esse artigo, a saber, (1) quais são as principais características desses grupos; e (2) qual é o perfil e como se comportam na arena parlamentar os integrantes que se elegeram à Câmara dos Deputados no pleito de 2018, a metodologia da pesquisa foi dividida em três frentes.

\footnotetext{
3 O compêndio completo de propostas pode ser acessado neste link: < https://mbl.org.br/wordpress/wpcontent/uploads/2017/05/propostas-mbl.pdf>. Acesso em 21 jun 2020.
} 
A primeira questão foi respondida com base em uma pesquisa exploratória sobre as organizações, coletadas em seus respectivos sítios eletrônicos, contas de Twitter e Instagram, e em algumas reportagens jornalísticas.

Quanto ao segundo ponto, foi realizado um levantamento estatístico com dados dos 513 deputados eleitos à Câmara Federal em 2018, destacando algumas características de seus perfis como raça, sexo, idade, escolaridade, ocupação e tipos de financiamento de campanha, verificando se há diferenças entre o perfil geral dos eleitos e dos que pertencem às organizações.

Além disso, para captar tendências quanto ao comportamento parlamentar, foi feito um levantamento do posicionamento dos parlamentares objeto dessa pesquisa no conjunto de votações nominais referentes à Proposta de Emenda Constitucional nº 6/2019, a PEC da Previdência, para averiguar se os deputados foram fiéis a seus partidos nessa matéria, que foi a mais complexa e polêmica proposta de reforma que tramitou no Congresso Nacional no ano de 2019. Para tanto, foram analisadas 44 votações realizadas em plenário nos dias 10, 11 e 12 de julho, e nos dias 6 e 7 de agosto de 2019. A coleta de dados foi feita no portal Dados Abertos da Câmara Federal. O conjunto de votações analisadas foi selecionado com a seguinte metodologia: primeiramente foi identificado na planilha de dados o id da votação que se refere à PEC 6/2019, e os números do id que correspondem às votações que ocorreram em plenário sobre a proposição. Em seguida, foram selecionadas para a análise as votações desse conjunto que possuíam dados de orientação de voto dos partidos. Por fim, foi feita a comparação entre a orientação de voto das legendas e o voto do parlamentar em cada uma dessas votações. Para isso, foram aplicados três tipos de teste estatísticos ao conjunto de dados. Para testar o nível de associação dos votos dos parlamentares e as orientações dos seus respectivos partidos foram utilizados o teste qui-quadrado $\left(\chi^{2}\right)$ de Pearson e o Teste de Fisher. Já para testar o nível de associação entre todas as orientações dos partidos e todos os votos dos parlamentares entre si, foi feita uma análise de correspondência múltipla no software Python.

\section{RESULTADOS}

\subsection{PERFIL}

A bancada de deputados da "renovação política" é formada por dez deputados. São eles: Felipe Rigoni (PSB), Joenia Wapichana (REDE), Kim Kataguiri (DEM), Lucas Gonzalez (NOVO), 
Luiz Lima (PSL), Marcelo Calero (Cidadania), Paulo Ganime (NOVO), Tiago Mitraud (NOVO), Tabata Amaral (PDT), e Vinicius Poit (NOVO). Com exceção de Kim Kataguiri, todos eles são líderes do RenovaBr e dois deles também são membros do Movimento Acredito, Felipe Rigoni e Tabata Amaral. A seguir a tabela 1 apresenta as principais características do perfil desses deputados:

TABELA 1 - DADOS SOBRE O PERFIL DOS DEPUTADOS FEDERAIS MEMBROS DAS ORGANIZAÇÕES PARAPARTIDÁRIAS:

\begin{tabular}{|c|c|c|c|c|c|c|c|c|}
\hline nome & partido & organização & estado & idade & sexo & escolaridade & cor/raça & ocupação \\
\hline $\begin{array}{l}\text { Lucas } \\
\text { Gonzalez }\end{array}$ & NOVO & Renovabr & $\mathrm{MG}$ & 30 & masculino & $\begin{array}{l}\text { superior } \\
\text { completo }\end{array}$ & branca & empresário \\
\hline $\begin{array}{l}\text { Marcelo } \\
\text { Calero }\end{array}$ & $\begin{array}{l}\text { Cida- } \\
\text { dania }\end{array}$ & Renovabr & RJ & 36 & masculino & $\begin{array}{l}\text { superior } \\
\text { completo }\end{array}$ & branca & advogado \\
\hline $\begin{array}{l}\text { Joenia } \\
\text { Wapichana }\end{array}$ & REDE & Renovabr & RR & 45 & feminino & $\begin{array}{l}\text { superior } \\
\text { completo }\end{array}$ & indígena & advogada \\
\hline $\begin{array}{l}\text { Felipe } \\
\text { Rigoni }\end{array}$ & PSB & $\begin{array}{l}\text { Renovabr e } \\
\text { acredito }\end{array}$ & $\mathrm{ES}$ & 27 & masculino & $\begin{array}{l}\text { superior } \\
\text { completo }\end{array}$ & branca & outros \\
\hline $\begin{array}{l}\text { Vinicius } \\
\text { Poit }\end{array}$ & NOVO & Renovabr & SP & 33 & masculino & $\begin{array}{l}\text { superior } \\
\text { completo }\end{array}$ & branca & administrador \\
\hline $\begin{array}{l}\text { Tiago } \\
\text { Mitraud }\end{array}$ & NOVO & Renovabr & $\mathrm{DF}$ & 32 & masculino & $\begin{array}{l}\text { superior } \\
\text { completo }\end{array}$ & branca & administrador \\
\hline $\begin{array}{l}\text { Tabata } \\
\text { Amaral }\end{array}$ & PDT & $\begin{array}{l}\text { Renovabr e } \\
\text { acredito }\end{array}$ & SP & 25 & feminino & $\begin{array}{l}\text { superior } \\
\text { completo }\end{array}$ & branca & $\begin{array}{l}\text { cientista } \\
\text { política }\end{array}$ \\
\hline $\begin{array}{l}\text { Paulo } \\
\text { Ganime }\end{array}$ & NOVO & Renovabr & $\mathrm{RJ}$ & 35 & masculino & $\begin{array}{l}\text { superior } \\
\text { completo }\end{array}$ & branca & engenheiro \\
\hline Luiz Lima & PSL & Renovabr & RJ & 41 & masculino & $\begin{array}{l}\text { superior } \\
\text { completo }\end{array}$ & parda & empresário \\
\hline $\begin{array}{l}\text { Kim } \\
\text { Kataguiri }\end{array}$ & DEM & MBL & SP & 23 & masculino & $\begin{array}{l}\text { superior } \\
\text { incompleto }\end{array}$ & amarela & escritor e crítico \\
\hline
\end{tabular}

Fonte: elaborada pela autora a partir do banco de dados do Tribunal Superior Eleitoral ${ }^{4}$.

De início é fácil perceber que essa bancada é predominantemente masculina, formada por oito homens e duas mulheres. Composição que não é inovadora, visto que dos 513 deputados federais eleitos $84 \%$ (436) deles são homens e apenas $26 \%$ (77) mulheres.

Em relação ao fator raça e cor, a bancada da renovação não apresentou grande diversidade racial, considerando que sete deles são brancos, um é pardo, um é amarelo, e uma é indígena. Entretanto, destaca-se o fato de que a Deputada Joênia (REDE-RR) é a primeira indígena eleita para

\footnotetext{
${ }^{4}$ O banco de dados foi disponibilizado por Fernando Zelinski, doutorando do Programa de Pós-Graduação em Ciência Política da UFPR.
} 
esse cargo na história do Brasil, representando sim, uma grande novidade em termos de representação da diversidade racial capitaneada pelo RenovaBR.

Quanto à totalidade dos deputados federais eleitos, vemos que há mais diversidade racial, já que $75 \%$ (385) deles são brancos, $20 \%$ pardos (104), 4\% (21) pretos, $0,3 \%$ (2) amarelos e 0,1\% (1) indígena.

Sobre o perfil do grau de instrução, dos pertencentes à bancada da renovação nove tem ensino superior completo, e um tem ensino superior incompleto, o que difere pouco da escolaridade geral dos eleitos, que tem $80 \%$ (414) com formação superior e cerca de 7\% (37) com formação superior incompleta. Na tabela a seguir pode-se ver com mais detalhes a escolaridade de todos deputados federais eleitos:

TABELA 2 - GRAU DE INSTRUÇÃO DOS DEPUTADOS FEDERIAS ELEITOS EM 2018.

\begin{tabular}{|l|c|c|}
\hline Escolaridade & quantidade & porcentagem \\
\hline Ensino fundamental completo & 10 & $1,9 \%$ \\
\hline Ensino fundamental incompleto & 5 & $0,9 \%$ \\
\hline Ensino médio completo & 44 & $8,5 \%$ \\
\hline Ensino médio incompleto & 2 & $0,3 \%$ \\
\hline Lê e escreve & 1 & $0,1 \%$ \\
\hline Superior completo & 414 & $80,7 \%$ \\
\hline Superior incompleto & 37 & $7,2 \%$ \\
\hline total & 513 & $100 \%$ \\
\hline
\end{tabular}

Fonte: elaborada pela autora a partir do banco de dados do Tribunal Superior Eleitoral

O levantamento da "ocupação" revelou que a bancada da renovação é formada por dois empresários, dois administradores, dois advogados, uma cientista política, um engenheiro, um escritor e crítico, e um sem definição. O conjunto total dos eleitos apresenta como ocupação predominante a de "político", somando 48,9\% (251) do total (sendo 45,6\% deles deputados e 3,3\% vereadores), seguido por “empresário", pontuando 10\% (52) deles, "advogados" são 7,8\% (40), seguidos por "médico" 3,7\% (19), engenheiro 2,7\% (14), administrador 2,7\% (14), e outras ocupações diversas que apresentam um porcentual ínfimo.

Percebe-se que o ponto mais discrepante da bancada da renovação é justamente não ter uma ocupação política, que é o caso de quase metade dos deputados federais eleitos em 2018. Mas quando observamos as outras ocupações predominantes do todo, vemos que a maioria delas são similares às ocupações da bancada da renovação, com exceção de "cientista política" e "escritor e crítico" que são as únicas entre todos os eleitos. 
Por fim, o quesito idade, a bancada da renovação é toda formada por pessoas que tinham entre 23 e 45 anos de idade no ano em que se elegeram, sendo que três parlamentares tinham menos de 30 anos, cinco deles, entre 31 e 40 anos, e dois com mais de 40 anos. Já o conjunto total dos eleitos apresenta um perfil mais envelhecido, conforme pode-se verificar na Tabela 3.

TABELA 3 - FAIXA ETÁRIA DOS DEPUTADOS FEDERAIS ELEITOS EM 2018 NA DATA DA POSSE:

\begin{tabular}{|l|c|c|}
\hline Faixa etária & quantidade & porcentagem \\
\hline até 30 anos & 26 & $5 \%$ \\
\hline de 31 a 40 anos & 111 & $21,6 \%$ \\
\hline de 41 a 50 anos & 137 & $26,7 \%$ \\
\hline 51 a 60 anos & 143 & $27,8 \%$ \\
\hline 60 anos ou mais & 96 & $18,7 \%$ \\
\hline total & 513 & 100,00 \\
\hline
\end{tabular}

Fonte: elaborada pela autora a partir do banco de dados do Tribunal Superior Eleitoral.

Concluída a apresentação dos aspectos que compõe o perfil dos deputados federais eleitos, relembre-se: sexo, raça, escolaridade, ocupação e idade, é visto que o perfil da bancada da renovação não é tão diferente assim do perfil geral. Ela é predominantemente masculina, branca, o que não são características inovadoras; possui um elevado grau de escolaridade, que é singular, porém não discrepante do todo; as ocupações não eram políticas, o que é uma grande diferença comparado ao todo; e o fator idade se demonstrou com uma das características mais inovadoras, visto que há um perfil mais jovem dentre os membros da bancada da renovação, em contraposição ao perfil geral que é mais envelhecido. Destaque-se também a questão da inovação ${ }^{5}$ no quesito da raça, por eleger a primeira deputada federal indígena.

O gráfico a seguir compara as características predominantes dos dois grupos.

\footnotetext{
${ }^{5}$ Outra inovação quanto ao perfil dos eleitos que não figurou nos aspectos aqui analisados, mas merece destaque, é o fato da bancada da renovação também apresentar o primeiro deficiente visual eleito para o cargo de Deputado Federal, o Felipe Rigoni. Devido a sua eleição, a Câmara teve de promover uma série de adaptações físicas e tecnológicas para permitir a acessibilidade do Deputado à Casa.
} 
GRÁFICO 1 - COMPARAÇÃO ENTRE AS CARACTERÍSTICAS PREDOMINANTES DO PERFIL DOS DEPUTADOS MEMBROS DE ORGANIZAÇÃO PARAPARTIDÁRIA X TOTAL DE DEPUTADOS FEDERAIS:

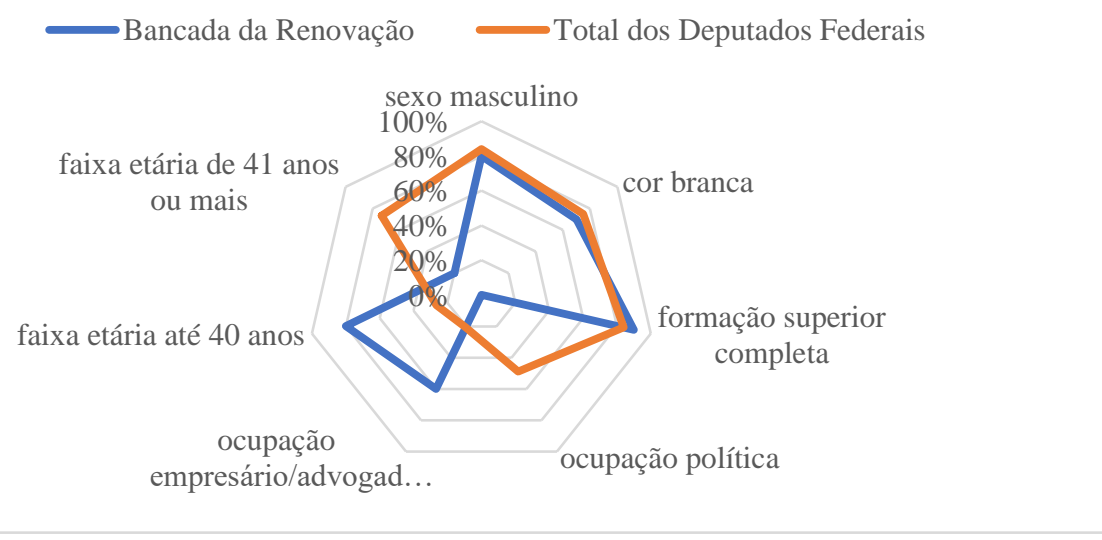

Fonte: elaborada pela autora a partir do banco de dados do Tribunal Superior Eleitoral.

\subsection{FINANCIAMENTO DE CAMPANHA}

Outro fator considerado relevante para classificar o perfil dos eleitos é com relação ao montante e às fontes de financiamento de campanha. Para isso, será comparado o montante de financiamento público e de financiamento privado utilizados pelos eleitos durante suas campanhas eleitorais. O financiamento público é composto pelos valores advindos do Fundo Especial de Financiamento de Campanha, criado pela Lei Federal n ${ }^{\circ}$ 13.488/17, e pelo Fundo Partidário previsto na Lei Federal $n^{\circ}$ 9.096/95. O financiamento privado se refere ao montante que tem como origem pessoas físicas ou mesmo os próprios candidatos; partidos políticos também podem ser fontes de recurso privado, quando são agentes intermediadores entre doadores pessoa física.

TABELA 4 - FONTES E VALORES DE FINANCIAMENTO DE CAMPANHA DOS DEPUTADOS FEDERAIS MEMBROS DE ORGANIZAÇÕES PARAPARTIDÁRIAS

\begin{tabular}{|l|c|c|c|}
\hline Nome & $\begin{array}{c}\text { Financiamento } \\
\text { Privado }\end{array}$ & Financiamento Publico & Financiamento Total \\
\hline Lucas Gonzalez & $\mathrm{R} \$ 664.682,43$ & $\mathrm{R} \$ 0,00$ & $\mathrm{R} \$ 664.682,43$ \\
\hline Marcelo Calero & $\mathrm{R} \$ 825.665,48$ & $\mathrm{R} \$ 347.056,75$ & $\mathrm{R} \$ 1.172 .722,23$ \\
\hline Joenia Wapichana & $\mathrm{R} \$ 89.035,13$ & $\mathrm{R} \$ 150.000,00$ & $\mathrm{R} \$ 239.035,13$ \\
\hline Felipe Rigoni & $\mathrm{R} \$ 759.395,37$ & $\mathrm{R} \$ 153.600,00$ & $\mathrm{R} \$ 912.995,37$ \\
\hline Vinicius Poit & $\mathrm{R} \$ 1.283 .047,97$ & $\mathrm{R} \$ 0,00$ & $\mathrm{R} \$ 1.283 .047,97$ \\
\hline Tiago Mitraud & $\mathrm{R} \$ 814.831,85$ & $\mathrm{R} \$ 0,00$ & $\mathrm{R} \$ 814.831,85$ \\
\hline Tabata Amaral & $\mathrm{R} \$ 1.190 .696,60$ & $\mathrm{R} \$ 100.000,00$ & $\mathrm{R} \$ 1.290 .696,60$ \\
\hline Paulo Ganime & $\mathrm{R} \$ 298.835,26$ & $\mathrm{R} \$ 0,00$ & $\mathrm{R} \$ 298.835,26$ \\
\hline Luiz Lima & $\mathrm{R} \$ 263.661,79$ & $\mathrm{R} \$ 0,00$ & $\mathrm{R} \$ 263.661,79$ \\
\hline Kim Kataguiri & $\mathrm{R} \$ 305.495,99$ & $\mathrm{R} \$ 0,00$ & $\mathrm{R} \$ 305.495,99$ \\
\hline Média & $\mathbf{R} \$ \mathbf{6 4 9 . 5 3 4 , 7 9}$ & $\mathbf{R} \$ \mathbf{7 5 . 0 6 5 , 6 8}$ & $\mathbf{R} \$ \mathbf{7 2 4 . 6 0 0 , 4 6}$ \\
\hline
\end{tabular}

Fonte: elaborada pela autora a partir do banco de dados do Tribunal Superior Eleitoral. 
Como pode-se observar na tabela 4, a média do financiamento público utilizado pela bancada da renovação ficou em 75 mil reais, já a média do financiamento privado ficou em 649 mil reais. Entre eles somente quatro utilizaram o financiamento público, tendo esse valor não passado de 350 mil por candidato.

Em relação ao financiamento privado, os valores variaram de 89 mil a 1,2 milhões de reais por candidato. Somente quatro deles tiveram financiamento abaixo de 305 mil reais, o restante apresentou valores acima de 600 mil reais, tendo dois deles investido mais de um milhão de reais em recursos privados na campanha.

TABELA 5 - FINANCIAMENTO PÚBLICO DE CAMPANHA DO TOTAL DE DEPUTADOS FEDERAIS ELEITOS EM 2018 POR FAIXAS DE VALORES:

\begin{tabular}{|l|c|c|}
\hline valor em R\$ & quantidade & porcentagem \\
\hline até 100 mil & 93 & $18,1 \%$ \\
\hline entre 101 mil e 500 mil & 68 & $13,2 \%$ \\
\hline entre 501 mil e 1 milhão & $\mathbf{1 5 5}$ & $\mathbf{3 0 , 2} \%$ \\
\hline mais que 1 milhão & $\mathbf{1 9 7}$ & $\mathbf{3 8 , 4} \%$ \\
\hline Total & 513 & $100 \%$ \\
\hline
\end{tabular}

Fonte: elaborada pela autora a partir do banco de dados do Tribunal Superior Eleitoral.

TABELA 6 - FINANCIAMENTO PRIVADO DE CAMPANHA DO TOTAL DE DEPUTADOS FEDERIAS ELEITOS EM 2018 POR FAIXA DE VALORES:

\begin{tabular}{|l|c|c|}
\hline valor em R\$ & quantidade & porcentagem \\
\hline até 100 mil & 238 & $46,3 \%$ \\
\hline entre 101 mil e 500 mil & 211 & $41,1 \%$ \\
\hline entre 501 mil e 1 milhão & $\mathbf{4 0}$ & $\mathbf{7 , 8} \%$ \\
\hline mais que 1 milhão & $\mathbf{2 4}$ & $\mathbf{4 , 6} \%$ \\
\hline Total & 513 & $100 \%$ \\
\hline
\end{tabular}

Fonte: elaborada pela autora a partir do banco de dados do Tribunal Superior Eleitoral.

Em relação ao financiamento de campanha do total dos deputados eleitos, os dados foram agrupados em faixas de valores para facilitar a visualização. Destaque-se que $68 \%$ dos deputados estão na faixa de valor que vai de 501 mil até mais de um milhão de reais no que se refere ao financiamento público, o que demonstra a forte dependência deles dessa fonte de financiamento.

Já quanto ao financiamento privado, apenas $12 \%$ do total de eleitos se enquadrou na faixa de valores que vai de 501 mil até mais de um milhão de reais.

Por fim, a média do financiamento público (calculado sobre os valores de todos os 513 eleitos) foi de 874 mil reais, e do privado, 240 mil reais. 
No Gráfico 2 é possível visualizar uma grande discrepância entre o tipo predominante de financiamento da bancada da renovação, que, como esperado, é fortemente calcada em fontes privadas, e no financiamento de campanha dominante para total dos eleitos, que tem como sua principal fonte os recursos públicos.

\section{GRÁFICO 2 - COMPARAÇÃO DO VALOR DE FINANCIAMENTO PÚBLICO E PRIVADO DE CAMPANHA EMPREGADO PELA BANCADA DA RENOVAÇÃO E PELO TOTAL DE DEPUTADOS FEDERAIS}

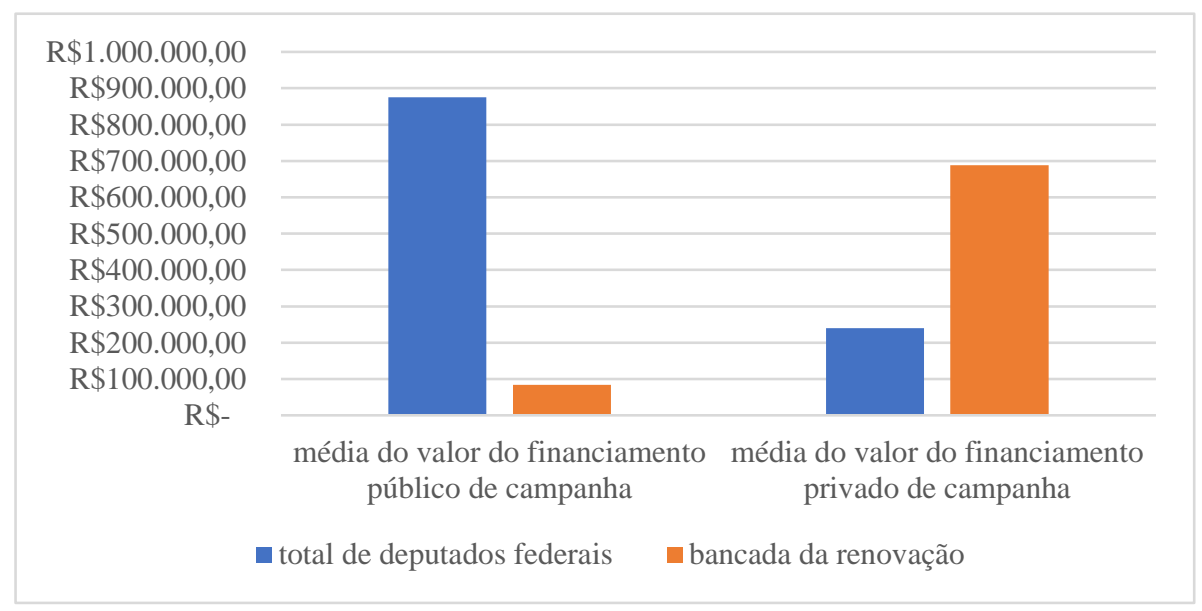

Fonte: elaborada pela autora a partir do banco de dados do Tribunal Superior Eleitoral.

A partir desse dado, é possível inferir que as organizações voltadas à renovação política foram profícuas em arregimentar doadores pessoas físicas para seus candidatos eleitos.

\section{3 - COMPORTAMENTO PARLAMENTAR}

A terceira parte deste trabalho consiste em analisar o comportamento parlamentar dos deputados da bancada da renovação, que será feita a partir do estudo de caso de 44 votações nominais relativas à votação da PEC da Reforma da Previdência.

A seguir estão as tabelas de comparação entre os votos dos parlamentares que compõe a bancada da renovação e a orientação de seus respectivos partidos ${ }^{6}$. As tabelas 7, 8, 9 e $10^{7}$ mostram o comportamento dos parlamentares do Partido Novo.

\footnotetext{
${ }^{6}$ Para a confecção das tabelas e dos testes estatísticos entre os parlamentares e os seus partidos foram considerados somente os posicionamentos "sim", "não" e "obstrução". Foram desconsiderados dados como "liberado", "abstenção" e "sem informação".

${ }^{7} \mathrm{Na}$ análise desses casos foi utilizado o teste estatístico de Fisher. O p-valor que aparece em cada tabela é o indicativo estatístico da significância do teste da amostra. $\mathrm{P}>0,05$ significa independência/dissociação, $\mathrm{P}<0,05$ significa dependência/associação. Assim, o "P" menor do que 0,05 significa que há alinhamento entre orientação partidária e voto do parlamentar; o "P" maior do que 0,05 significa que não há alinhamento.
} 


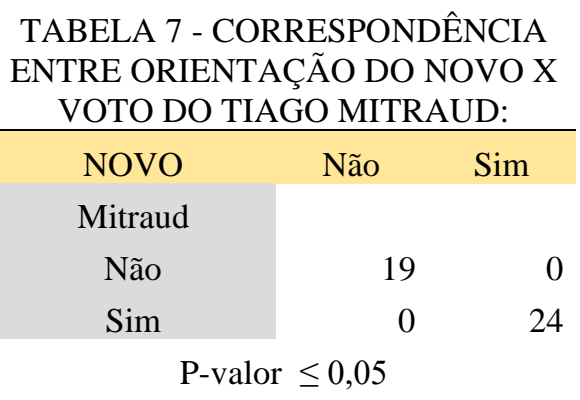

Fonte: Gerados por Victor Garcia Miranda a partir do banco de dados elaborado pela autora

\begin{tabular}{lrr}
\multicolumn{4}{c}{ TABELA 9 - CORRESPONDÊNCIA } \\
ENTRE ORIENTAÇÃO DO NOVO X \\
\multicolumn{4}{c}{ VOTO DO LUCAS GONZALES: } \\
\hline NOVO & Não & \multicolumn{1}{c}{ Sim } \\
Gonzales & & \\
Não & 18 & 0 \\
Sim & 0 & 23 \\
\multicolumn{4}{r}{ P-valor $\leq 0,05$}
\end{tabular}

Fonte: Gerados por Victor Garcia Miranda a partir do banco de dados elaborado pela autora

\begin{tabular}{|c|c|c|}
\hline NOVO & Não & Sim \\
\hline Poit & & \\
\hline Não & 19 & 0 \\
\hline Sim & 0 & 24 \\
\hline
\end{tabular}

TABELA 10 - CORRESPONDÊNCIA ENTRE ORIENTAÇÃO DO NOVO X VOTO DO PAULO GANIME:

\begin{tabular}{crr}
\hline NOVO & Não & \multicolumn{1}{c}{ Sim } \\
Ganime & & \\
Não & 19 & 0 \\
Sim & 0 & 24 \\
\multicolumn{2}{c}{ P-valor $\leq 0,05$} &
\end{tabular}

A partir dos dados apresentados nas tabelas acima, é possível perceber que os parlamentares do Novo votaram de forma altamente disciplinada com o partido na votação da PEC da Previdência.

As tabelas 11, 12 e 13 mostram o comportamento dos parlamentares Luiz Lima, Marcelo Calero e Kim Kataguiri em relação aos seus respectivos partidos. A partir dos dados é possível verificar que eles também tiveram um comportamento fiel aos seus partidos na votação da PEC da Previdência.

\begin{tabular}{ccc}
\multicolumn{4}{c}{ TABELA } & \multicolumn{3}{c}{ CORRESPONDÊNCIA } \\
ENTRE ORIENTAÇÃO DO PSL X \\
\multicolumn{3}{c}{ VOTO DO LUIZ LIMA: } \\
\hline PSL & não & sim \\
Lima & & \\
Não & 17 & 0 \\
Sim & 2 & 22 \\
\multicolumn{3}{r}{ P-valor $\leq 0,05$}
\end{tabular}

Fonte: Gerados por Victor Garcia Miranda a partir do banco de dados elaborado pela autora.
TABELA 12 - CORRESPONDÊNCIA ENTRE ORIENTAÇÃO DO CIDADANIA X VOTO DO MARCELO CALERO:

\begin{tabular}{c|cc|}
\hline CDN & Não & Sim \\
Calero & & \\
Não & 19 & 2 \\
Sim & 1 & 20 \\
\multicolumn{2}{c}{ P-valor $\leq 0,05$} \\
\end{tabular}

\author{
TABELA 13 - CORRESPONDÊNCIA \\ ENTRE ORIENTAÇÃO DO \\ DEMOCRATAS X VOTO DO KIM \\ KATAGUIRI:

DEM Não Sim




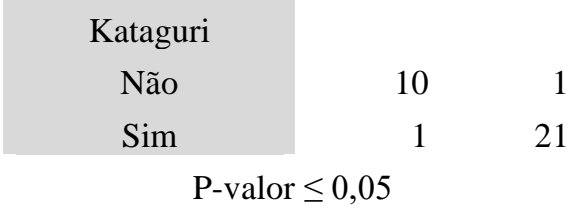

Fonte: Gerado por Victor Garcia Miranda a partir do banco de dados elaborado pela autora

A seguir estão os casos de comportamento parlamentar que apresentaram mais complexidade do que os mencionados até o momento. As tabelas 14,15 e $16^{8}$ mostram o comportamento dos parlamentares Joênia Wapichana, Felipe Rigoni e Tabata Amaral.

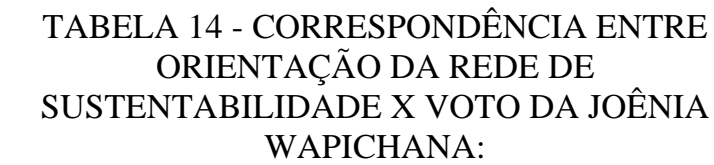

\begin{tabular}{cccc}
\hline REDE & Não & Obstrução & Sim \\
Wapichana & & 0 & 0 \\
Não & 4 & 1 & 0 \\
Obstrução & 0 & 0 & 2 \\
Sim & 0 & & \\
& p-valor $\leq 0,05$ &
\end{tabular}

Fonte: Gerados por Victor Garcia Miranda a partir do banco de dados elaborado pela autora

TABELA 15 - CORRESPONDÊNCIA ENTRE ORIENTAÇÃO DO PDT X VOTO DA TABATA AMARAL:

\begin{tabular}{|c|ccc|}
\hline PDT & Não & Obstrução & Sim \\
Amaral & & & \\
Não & 10 & 7 & 4 \\
Sim & 8 & 3 & 5 \\
\hline
\end{tabular}

Fonte: Gerados por Victor Garcia Miranda a partir do banco de dados elaborado pela autora
TABELA 16 - CORRESPONDÊNCIA ENTRE ORIENTAÇÃO DO PSB X VOTO DO FELIPE RIGONI:

$\begin{array}{cccc}\text { PSB } & \text { Não } & \text { Obstrução } & \text { Sim } \\ \text { Rigoni } & & & \\ \text { Não } & 7 & 6 & 6 \\ \text { Sim } & 12 & 1 & 6\end{array}$

A Tabela 14 apresenta como peculiaridade o fato de a REDE não ter orientado votos para a maioria das votações do conjunto em análise. Porém, nos casos em que há a orientação percebe-se que foi acatada pela Deputada Joênia, sendo que o resultado do teste estatístico foi de significância para o alinhamento entre o partido e a parlamentar. Já em relação aos casos do comportamento da Tabata Amaral e do Felipe Rigoni, o teste estatístico revelou que há dissociação entre os votos dos parlamentares e a orientação de seus respectivos partidos.

\footnotetext{
${ }^{8}$ Nas tabelas 14, 15 e 16 foi aplicado o teste estatístico x2 (qui-quadrado), pois nesses casos o valor "obstrução" apareceu na análise, tornando-a não-binária.
} 
A partir desses dados, pode-se concluir que a maioria dos parlamentares da bancada da renovação apresentou comportamento fiel aos seus respectivos partidos na votação da PEC da Previdência, com exceção de Tabata Amaral e Felipe Rigoni. A seguir o caso deles será analisado de forma mais aprofundada, pois além de serem infiéis a seus partidos, esses dois parlamentarem também são os únicos em análise que fazem parte do Movimento Acredito.

\section{GRÁFICO 3 - COMPARAÇÃO ENTRE A ORIENTAÇÃO DO PSB E O VOTO DE FELIPE RIGONI:}

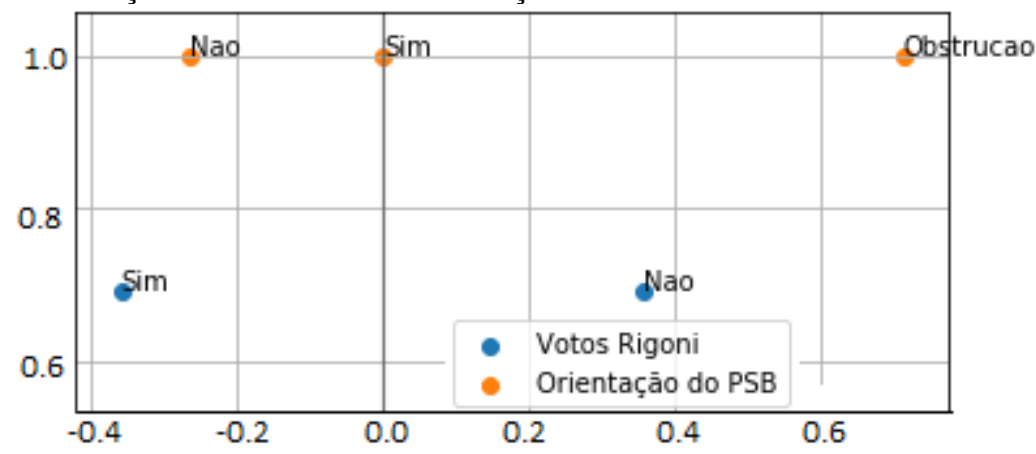

Fonte: elaborado por Victor Miranda a partir do banco de dados da autora.

GRÁFICO 4 - COMPARAÇÃO ENTRE A ORIENTAÇÃO DO PDT E O VOTO DA TABATA AMARAL:

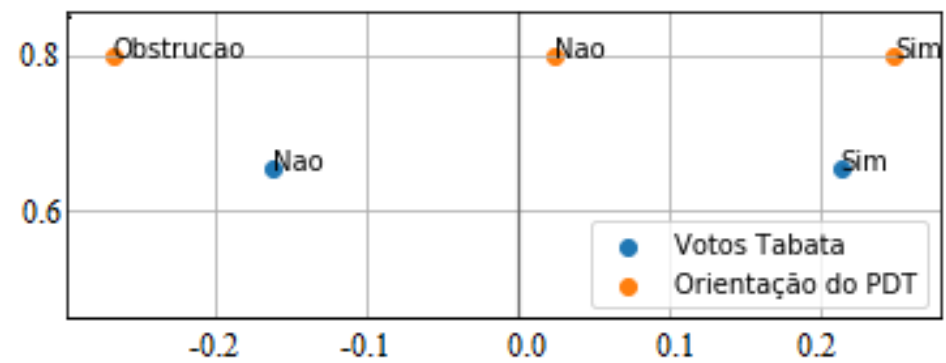

Fonte: elaborado por Victor Miranda a partir do banco de dados da autora.

Ao observar os gráficos, pode-se sugerir que o comportamento de Rigoni se caracteriza pelo voto frontalmente contrário ao partido, enquanto Tabata tem traços de votos mais aproximados à legenda. Pela falta de lealdade aos seus partidos, que se posicionaram contrários à PEC da Previdência, os dois deputados sofreram punições por parte da agremiação ${ }^{9}$. Posteriormente, o caso destes parlamentares será tratado com mais profundidade.

Concluída a parte de comparação de pares entre o parlamentar e o partido, a seguir, no gráfico 5 será analisado se os parlamentares votam de maneira semelhante entre si, a fim de verificar se eles têm um posicionamento convergente por fazerem parte de uma mesma organização suprapartidária,

\footnotetext{
${ }^{9}$ Disponível em: <https://www.correiobraziliense.com.br/app/noticia/politica/2019/07/16/interna_politica,771173/pdte-psb-decidem-o-destino-de-deputados-que-apoiaram-previdencia.shtml〉. Acesso em 9 jun 2019.
} 
qual seja, o RenovaBR (com exceção de Kim Kataguiri). A análise das posições do gráfico deve ser feita considerando cada dimensão separadamente.

\section{GRÁFICO 5 - ANÁLISE DE CORRESPONDÊNCIA MÚLTIPLA ENTRE OS VOTOS DOS PARLAMENTARES MEMBROS DE ORGANIZAÇÕES PARAPARTIDÁRIAS E AS ORIENTAÇÕES DOS SEUS RESPECTIVOS PARTIDOS:}

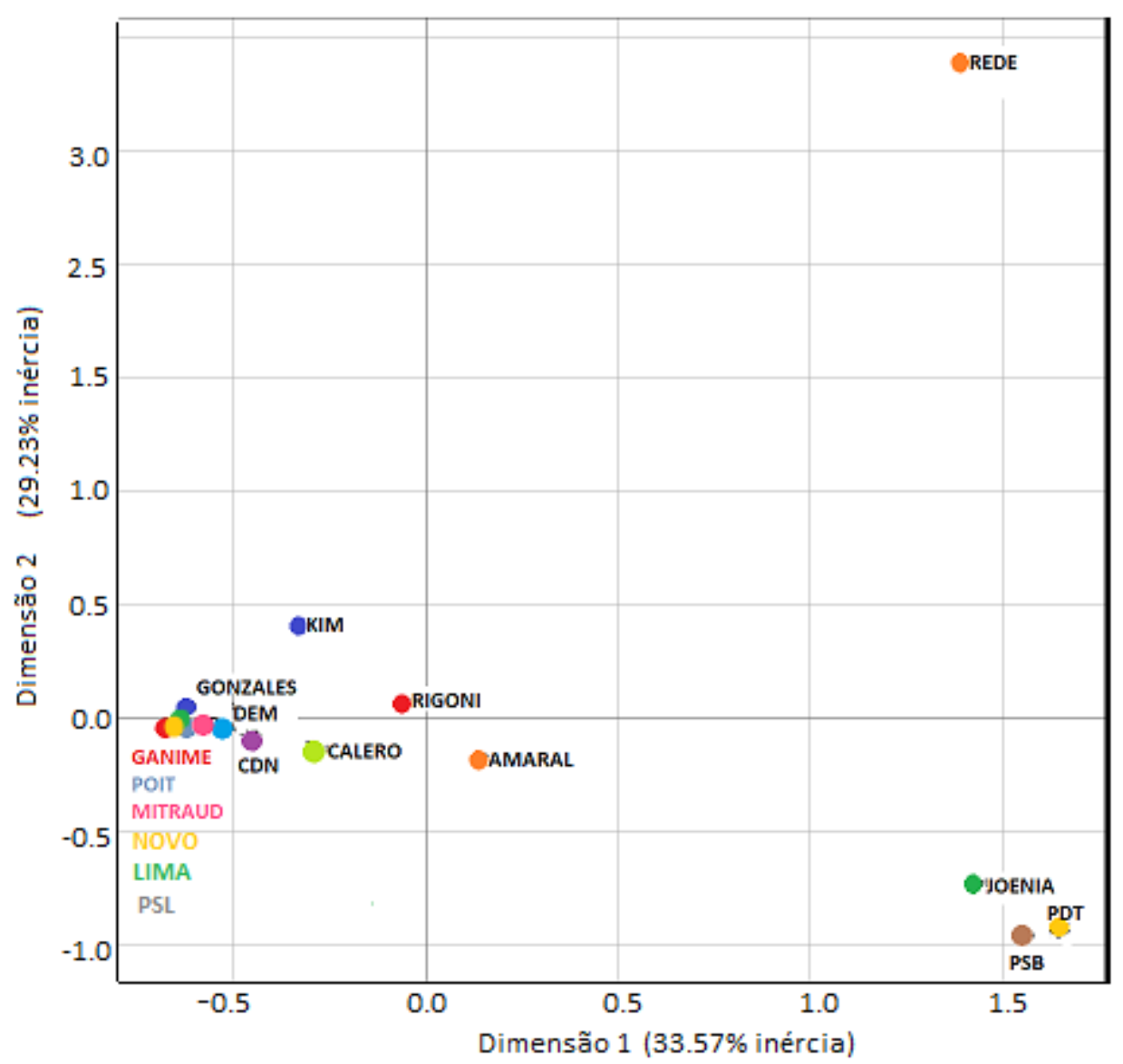

Fonte: Gerado por Victor Garcia Miranda a partir do banco de dados elaborado pela autora

É possível observar no gráfico que não há uma convergência de posicionamento entre todos os dez parlamentares, e nem entre os nove que fazem parte do RenovaBR. Entretanto, o gráfico permite ponderar o nível de proximidade dos votos de cada um deles e encontrar outros tipos de associação. Por exemplo, os deputados do partido Novo, Mitraud, Poit, Ganime e Gonzales, e o Luiz Lima, do PSL, estão praticamente sobrepostos no gráfico, sugerindo grande alinhamento no comportamento deles. Um pouco mais distante deles, considerando a dimensão 1, está Kim Kataguri, (DEM e MBL). Já Calero, Rigoni e Amaral estão mais distantes desse grupo, considerando a 
dimensão 2. Wapichana é a deputada que está mais distante de todos os outros nessa análise ${ }^{10}$. Com exceção dela, todos os outros parlamentares tiveram posicionamentos mais próximos aos partidos de direita, como NOVO, DEM e PSL, e distantes dos partidos de esquerda, PDT, PSB e REDE.

Verificado o fato de que não há convergência de posicionamento na bancada do RenovaBR, resta avaliar com mais profundidade a convergência dos votos dos membros da outra organização suprapartidária em análise neste trabalho, o Movimento Acredito. Na tabela 17 pode-se verificar se há associação entre os votos de Tabata Amaral e Felipe Rigoni nas votações da PEC da Previdência:

\begin{tabular}{c|rr} 
TABELA 17 - CORRESPONDÊNCIA \\
ENTRE OS VOTOS DE FELIPE \\
RIGONI E TABATA AMARAL: \\
Rigoni & Não & Sim \\
Amaral & & \\
\hline Abstenção & 1 & 0 \\
Não & 15 & 4 \\
Sim & 1 & 15 \\
\hline
\end{tabular}

p-valor $<0,05$

Fonte: Elaborada por Victor Miranda a partir do banco de dados da autora.

Com base na tabela, pode-se perceber a convergência entre os votos dos dois parlamentares, verificado também que há significância estatística do p-valor para a comparação dos votos. Mas como se trata de apenas dois parlamentares, Tabata e Felipe, não é possível afirmar se essa convergência se dá em função do tamanho diminuto da bancada ou se por fidelidade aos preceitos do Acredito. Importante mencionar que na época da votação da PEC da Previdência, o Acredito divulgou em sua conta no Instagram ${ }^{11}$ o posicionamento oficial sobre como e porque os parlamentares do grupo votariam a favor da PEC, justificando que o compromisso com a reforma já era uma pauta antiga do grupo.

Aqui é pertinente pontuar que a bancada do Movimento Acredito no Congresso é notadamente um caso particular entre as organizações objeto deste artigo. Ela possui um gabinete compartilhado entre os deputados federais Tabata Amaral, Felipe Rigoni e o Senador Alessandro Vieira (todos também fazem parte do RenovaBR). O compartilhamento de espaço físico e da assessoria é mais comum nos gabinetes das lideranças partidárias da Câmara. Vários cargos desse gabinete foram

\footnotetext{
${ }^{10} \mathrm{O}$ gráfico tem um nível de confiabilidade de $62,8 \%$ (soma da porcentagem das dimensões 1 e 2 ), calculado com base no Alfa de Cronbach.

${ }^{11}$ Post divulgado no app Instagram no dia 10 de julho de 2019, disponível em:

<https://www.instagram.com/p/BzwBpRPhr-q/?hl=pt-br>. Acesso em 9 jun 2020.
} 
preenchidos por meio de processo seletivo realizado pelo Programa Talentos do Congresso. A contratação de assessores via tal processo não é comum no Congresso. Além disso, os três parlamentares procuram produzir ações coordenadas, como a proposição de emendas, requerimentos, e até de ações judiciais em conjunto, comportando-se como se fossem, de fato, a bancada de um partido unido. Todas essas ações coordenadas são divulgadas nas redes sociais do movimento.

Concluída a análise dos dados, é possível constatar que a hipótese de que os representantes desses grupos apresentam elementos inovadores em seu perfil político e comportamento parlamentar incomum, quando comparados ao total dos deputados federais foi confirmada apenas em partes: a análise do perfil desses deputados demonstrou poucos elementos destoantes de todo o conjunto de deputados eleitos; e o estudo de caso do comportamento parlamentar demonstrou que a maioria deles vota de maneira alinhada ao seu partido, e não à organização suprapartidária, com exceção de dois parlamentares que apresentam elementos suficientes para serem estudados como uma caso a parte dentro do grupo.

\section{CONSIDERAÇÕES FINAIS}

Esta pesquisa foi uma primeira aproximação do objeto das organizações suprapartidárias de renovação política e do perfil de seus membros eleitos à Câmara Federal. Os resultados permitem verificar que em termos de atuação, o RenovaBR e o Movimento Acredito têm características que se assemelham aos partidos políticos, mas cada um possui modos de atuação próprios. O RenovaBR atua mais fortemente na formação e no financiamento de novas lideranças políticas que querem concorrer a um cargo eletivo, mas os participantes não necessariamente compartilham ideologias. Já o Acredito não atua como uma "incubadora" de candidatos, mas apresenta uma bancada mais coesa, em que os membros possuem pautas em comum e os representantes eleitos procuram sintonia em sua atuação parlamentar. Acerca do MBL não foi possível compreender novas características sobre ele com os achados desta pesquisa, em grande medida porque há somente um representante desse Movimento em análise.

Outro ponto que se destaca é que embora o perfil geral da bancada da renovação não seja inovador, ela trouxe alguns perfis inéditos para a Câmara, como uma indígena e um deficiente visual, bem como, o de jovens de menos de 30 anos que não tem parentes na política. É preciso refletir sobre se esses perfis chegariam ao Congresso sem o suporte dessas organizações. Assim, uma questão que 
se apresenta no horizonte da pesquisa é investigar como esses grupos recrutam seus membros e selecionam seus candidatos.

Um dos achados mais importantes da pesquisa foi aferir a importância das fontes privadas no financiamento da campanha desses deputados. Isso demonstra a habilidade das organizações, principalmente do RenovaBR, em arregimentar doações para campanhas. Em seu relatório de prestação de contas o RenovaBR diz ter contado com cerca de 1.800 doadores. Um apontamento para agenda de pesquisa resultado deste artigo seria investigar também as fontes de financiamento de campanha dos demais candidatos advindos desses movimentos, a fim de verificar se também tiveram um volume grande de recursos privados no financiamento de suas campanhas.

Outra possibilidade de pesquisa é a comparação do perfil dos deputados federais membros de organizações suprapartidárias x o perfil do restante dos deputados que se elegeram pela primeira vez para o cargo em 2018, já que o índice de renovação da Câmara Federal nessa eleição foi de 47,3\%, o mais alto desde a redemocratização. A partir dessa pesquisa seria possível averiguar de forma ainda mais profícua as peculiaridades das lideranças políticas formadas por essas organizações.

\section{REFERÊNCIAS}

AZEVEDO, Alessandra. PDT e PSB começam a decidir o destino de deputados que apoiaram Previdência. Correio Braziliense. Brasília, 16, julho, 2019. Disponível em: <https://www.correiobraziliense.com.br/app/noticia/politica/2019/07/16/interna_politica,771173/pd t-e-psb-decidem-o-destino-de-deputados-que-apoiaram-previdencia.shtml>. Acesso em 9 jun 2020.

Conta do Instagram do Movimento Acredito. Posicionamento do Acredito sobre a reforma da previdência. Publicado no dia 10 de julho de 2019, disponível em: <https://www.instagram.com/p/BzwBpRPhr-q/?hl=pt-br>. Acesso em 9 jun 2020.

Conta de Twitter do Movimento Brasil Livre. Disponível em: 〈https://twitter.com/MBLivre〉. Acesso em 22 set 2020 .

MOVIMENTO BRASIL LIVRE. Propostas aprovadas no primeiro congresso nacional do Movimento Brasil Livre em novembro de 2015. Disponível em: <https://mbl.org.br/wordpress/wpcontent/uploads/2017/05/propostas-mbl.pdf>. Acesso em 21 jun 2020.

Portal Dados Abertos da Câmara dos Deputados. Disponível em: <https://dadosabertos.camara.leg.br/>. Acesso entre abril e maio 2020.

RENOVABR. Relatório Anual 2018. RenovaBR. Disponível em: https://media.renovabr.org/uploads/2020/07/Relat\%C3\%B3rio-2018.pdf. Acesso em 25 mai 2020.

Sítio Eletrônico do Movimento Acredito. Disponível em: 〈https://movimentoacredito.org/〉. Acesso em 16 jun 2020. 
Sítio Eletrônico do Movimento Brasil Livre. Disponível em: 〈https://mbl.org.br/>. Acesso em 21 jun 2020.

Sítio Eletrônico do RenovaBR. Disponível em: 〈https://renovabr.org/> Acesso em 25 mai 2020. 